WESTDEUTSCHE LITERATUR IN DER DDR 
IRENE CHARLOTTE STREUL

\title{
Westdeutsche Literatur in der DDR
}

\author{
Böll, Grass, Walser und andere \\ in der offiziellen Rezeption 1949 - 1985
}


CIP-Kurztitelaufnahme der Deutschen Bibliothek

Streul, Irene Charlotte:

Westdeutsche Literatur in der DDR : Böll, Grass, Walser u. a. in d. offiziellen Rezeption 1949 - 1985 / Irene Charlotte Streul. - Stuttgart : Metzler, 1988.

(Metzler Studienausgabe)

ISBN 978-3-476-00621-9

ISBN 978-3-476-00621-9

ISBN 978-3-476-03246-1 (eBook)

DOI 10.1007/978-3-476-03246-1

Dieses Werk einschließlich aller seiner Teile ist urheberrechtlich geschützt. Jede Verwertung außerhalb der engen Grenzen des Urheberrechtsgesetzes ist ohne Zustimmung des Verlages unzulässig und strafbar. Das gilt insbesondere für Vervielfältigungen, Übersetzungen, Mikroverfilmungen und die Einspeicherung und Verarbeitung in elektronischen Systemen.

(C) 1988 Springer-Verlag GmbH Deutschland Ursprünglich erschienen bei J.B. Metzlersche Verlagsbuchhandlung und Carl Ernst Poeschel Verlag GmbH in Stuttgart 1988 


\section{INHALTSVERZEICHNIS}

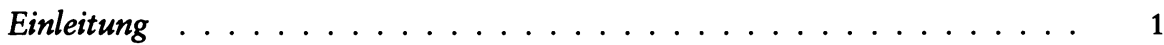

\section{Gesellschaftliche Bedingungen für die Aufnahme}

der westdeutschen Literatur in der DDR . . . . . . . . . . . . . . . 5

1. Kulturpolitische Voraussetzungen der Rezeption(1945-1971) . . . . . . . 5 5

2. Vermittlungsinstanzen ...................... 20

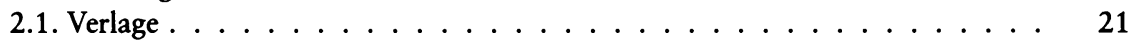

2.2. Periodika . . . . . . . . . . . . . . . . . 23

2.3. Literaturkritik und Literaturwissenschaft . . . . . . . . . . . . . 26

II. Haupttendenzen des Rezeptionsprozesses(1949-1961) . . . . . . . . . . 31

1. Dichotomie der westdeutschen Literatur . . . . . . . . . . . . . . . . . . . . . . . . . . . . . . . . . .

2. Die Rezeption der Kriegsliteratur . . . . . . . . . . . . . . . . . 33

2.1. Der Erkenntniswert der Kriegsliteratur . . . . . . . . . . . . . 36

2.2. Zwischen Apologie und Gesellschaftskritik - Problematische Urteilsfindung über die Romane Hans Hellmut Kirsts . . . . . . . . . . . . . . . . . 38

2.3. Die "oppositionelle Kriegsliteratur"-Gert Ledig, Wolfgang Ott, Hans Werner Pump, Karlludwig Opitz . . . . . . . . . . . . . . 40

2.4. Umorientierung in der Rezeption der Kriegsliteratur . . . . . . . . . . . . 42

2.5. Funktionale Aspekte der Rezeption . . . . . . . . . . . . . . . 46

3. Ideologische Deutungsmuster der zeitkritischen Erzählliteratur . . . . . . . . 47

3.1. Literatur als Widerspiegelung gesellschaftlicher Verhältnisse in Westdeutschland . . . . . . . . . . . . . . . 48

3.2. Textaneignung als Ideologiekritik . . . . . . . . . . . . . . 50

3.3. Die Refaschisierungsthese . . . . . . . . . . . . . . . . . . . 53

3.4. Politische Zeitereignisse als Bezugspunkt literaturwissenschaftlicher Rezeption . 55

3.5. Erste Bilanzierung und Klassifikation . . . . . . . . . . . . . . . 57

3.6. V. Deutscher Schriftstellerkongreß 1961 - Anna Seghers' Kritik an der Schablonenhaftigkeit der Literaturbetrachtung . . . . . . . . . . . 60

3.7. Distanz und Kontaktsuche - Literarische Kommunikation als Instrument der Bündnispolitik . . . . . . . . . . . . . . . . 61 
Inhaltsverzeichnis

III. Die Aufnahme der westdeutschen Literatur in den 60er und frühen 70er Jahren-Kategorisierung und Kanonbildung . . . . . . . . . . . . . . 65

1. Typologie der Rezeption . . . . . . . . . . . . . . . 65

2. Die Dekadenzdiskussion . . . . . . . . . . . . . . . 66

2.1. Die offiziöse Definition von Dekadenz . . . . . . . . . . . . . . . . . . . 67

2.2. Die Rezeption bürgerlicher Literatur als Dekadenzliteratur . . . . . . . . . . . 69

2.2.1. Gesellschafts- und zeitorientierte Texte . . . . . . . . . . . . 71

2.2.2. Die unpolitische Gegenwartsliteratur . . . . . . . . . . . . . 71

2.3. Gegenstimmen - Lukács, Fischer, Hermlin, Auer . . . . . . . . . . . 73

2.4. Modifizierung des Dekadenzbegriffs . . . . . . . . . . . . . . 75

3. Menschenbild - Hauptgesichtspunkt bei der Untersuchung der epischen

Literatur Westdeutschlands . . . . . . . . . . . . . . . . . . 78

3.1. Methoden zur Bestimmung des Menschenbildes . . . . . . . . . . . . 78

3.2. Menschenbildmodelle . . . . . . . . . . . . . . . . . . 80

3.2.1. Die Ohnmacht des Individuums gegenüber einer undurchschaubaren, bedrohlichen Welt(von Cramer, Johnson) . . . . . . . . . . 81

3.2.2. Der Bewußtseinshorizont des Kleinbürgers(Grass, Walser) . . . . . . . . 84

3.2.3. Der Mensch auf dem Rückzug aus der Gesellschaft(Andersch, Böll) . . . . 91

3.2.4. Die moralische Verantwortlichkeit des Menschen(S. Lenz) . . . . . . . . 97

3.2.5. Der zum biologischen Funktionsmechanismus deformierte Mensch (Neuer Realismus/Kölner Schule) . . . . . . . . . . . . . . . . . . . . 101

3.2.6. Die aktive, auf Veränderung der Gesellschaft zielende Position (Valentin, Weiss . . . . . . . . . . . . . . . . . . 107

3.2.7. Die Arbeitergestalt in der Literatur der Gruppe 61 (v. d. Grün, Geißler) . . . 111

4. Nähe und Distanz - Die Rezeption der Werke Heinrich Bölls ～. . . . . . . . 117

IV. Die Rezeption der Literatur aus der Bundesrepublik im Wandel

(1971 bis 1985) . . . . . . . . . . . . . . . . . . . 128

1. Veränderung des gesellschaftlichen Bedingungsrahmens . . . . . . . . . . . 128

1.1. Modifikation der Kulturpolitik seit 1971 . . . . . . . . . . . . . . . . . 128

1.2. Theoretischer und methodologischer Positionswechsel . . . . . . . . . . . 132

2. Literatur mit antikapitalistischer Tendenzbevorzugter Gegenstand der Rezeption . . . . . . . . . . . . . . . . . . . . . 135

2.1. Klassifikationsmerkmale . . . . . . . . . . . . . . . . . . . . 135

2.2. Gebrauchswert der Literatur im Klassenkampf . . . . . . . . . . . . . . 137

2.2.1. Reportage- und Dokumentarliteratur . . . . . . . . . . . . . . . 138

2.2.2. Prosaliteratur im Umkreis der DKP . . . . . . . . . . . . . . . . . . 141

2.3. Reaktionen auf den Standortwechsel Martin Walsers . . . . . . . . . . . . . 143

3. Neue Aspekte bei der Bewertung der Prosaliteratur am Beginn der achtziger Jahre . . . . . . . . . . . . . . .

4. Erste Gesamtdarstellung zur Geschichte der Literatur der Bundesrepublik Deutschland (1983) 
Anmerkungen . . . . . . . . . . . . . . . . . . 157

Anhang . . . . . . . . . . . . . . . . . . . . . . . . . 189

Lizenzausgaben westdeutscher Literatur in der DDR . . . . . . . . . 190

Lizenzausgaben österreichischer und schweizerischer Literatur . . . . . . . . . . 195

Literaturverzeichnis . . . . . . . . . . . . . . . . 196

Nachschlagewerke . . . . . . . . . . . . . . . . . 207

Abkürzungsverzeichnis . . . . . . . . . . . . . . . . 208

Personenregister . . . . . . . . . . . . . . . . 209 